\title{
Symbolic, Relational, and Ideological Signifiers of Bias-Motivated Offenders: Toward a Strategy of Assessment
}

\author{
Edward Dunbar, EdD \\ University of California, Los Angeles
}

\begin{abstract}
Developmental, ideological, and behavioral characteristics of 58 convicted hate crime offenders were examined. Ratings on the Psychopathy Checklist: Screening Version, HCR-20, and Bias Motivation Profile (BMP) were made via record review. Offense characteristics were rated on the Cornell Aggression Index and Cormier-Lang Crime Index. Results indicated that offenders with higher BMP scores engaged in more instrumental (i.e., premeditated) aggression and targeted racial-ethnic minority victims. Significant within-group variation in the prominence of offender bias motivation on the BMP was observed.
\end{abstract}

Hate crimes constitute a special class of violence. In the United States, since the enactment of federal hate crime laws in 1990, bias-motivated crimes have garnered national attention. Although social psychological research concerning hate crimes has provided insight into the factors that lead to intergroup violence (Ehrlich, 1992; Green, Glaser, \& Rich, 1998; Herek, Gillis, Cogan, \& Glunt, 1996), information concerning individual difference variables of bias offenders is to date unavailable.

There is significant debate about whether an offender's bias motivation can be reliably identified (Sullaway, in press). This has led some theorists to argue for the repeal of hate crime laws altogether (Jacobs \& Potter, 1998). The successful prosecution of the bias-motivated offender requires that there is a discernible behavioral and volitional component present in the offense. This is essential if the offense is to meet the standard of legal intent, as defined under state and federal laws (Levin, 1999). Determining the validity of the bias motivation is compromised by the limited information concerning the perpetrators of hate crimes. This knowledge gap has allowed for psychological theory to be used in arguing against an offender's culpability (Dunbar, 1999). This study examined bias motivation through behavioral analysis of the offense and examination of the histories of convicted hate crime offenders.

For reprints and correspondence: Edward Dunbar, EdD, Department of Psychology/Center for the Study and Resolution of Interethnic/Interracial Conflict, University of California, Los Angeles, California 90024. E-mail: edunbar@ucla.edu

\section{Bias Motivation as a Multidimensional Construct}

In the United States, a crime that is motivated in whole or in part by the perpetrator's bias toward the victim's social in-group may be prosecuted as a hate crime. Acts of bias speech that do not occur in conjunction with a separate criminal offense are protected free speech under the First Amendment. These acts are identified as "hate incidents" and are not prosecuted under state or federal law. A hate crime must include both a criminal offense (i.e., physical assault) and evidence of a bias motivation (e.g., bias toward gay men that led to the selection of a specific crime victim).

However, what indicates an offender's bias motivation in the commission of a hate crime? Routinely, law enforcement officers and prosecutors consider bias motivation in terms of the presence of hate speech, which occurs concurrently with the perpetration of a crime. This constitutes an unduly narrow standard under the current statutes. A more comprehensive understanding of bias motivation would use a systematic analysis of the offender's attitudes and behaviors. It is proposed that, in addition to hate speech, valid bias signifiers include the offender's articulated beliefs of in-group superiority, their affiliation with social cohorts who espouse a hate-based worldview, the display of symbols that communicate this hatebased worldview (e.g., dress, iconography, and art), and a history of (perpetrating) bias-motivated aggression. These symbolic (dress) and relational (affiliation with members of a hate-motivated gang) components may indicate a more enduring form of bias motivation than hate speech. Symbolic and relational signifiers 
underscore the desire of the offender to impact his or her social environment as well.

Inclusion of these behavioral, relational, and symbolic components allows for a more precise analysis of both the presence and degree (i.e., prominence) of bias motivation in hate crimes. This information can assist in the determination of offender culpability, appropriate sentencing options, and logic of prosecution under the penalty enhancement established under hate crime laws. Treating bias motivation as a multidimensional construct can additionally assist in tailoring rehabilitation efforts to reduce offender bias orientation.

\section{Behavioral Characteristics of Bias Aggression}

Given that the majority of hate crimes are violent acts against the person (Levin, 1999), analysis of the characteristics of aggression in these cases is particularly important. The bias-motivated offender frequently acts as either a defender of his or her in-group or plays the role of the aggressor against members of a competing social out-group. The motivation to perpetrate a hate crime is characteristic of reactive (i.e., defending) and instrumental (i.e., socially dominant) violence, respectively (Berkowitz, 1993). Instrumental aggression is marked by planning (i.e., premeditation) and goal pursuit (i.e., achievement of a desired outcome or experience). By comparison, reactive crimes are spontaneous and characterized by aggression against perceived provocation. Research on instrumental aggression has suggested that it constitutes an enduring behavioral strategy of the individual. The numerous studies of Pulkinnen and her colleagues (Pulkinnen, 1987) with children and adolescents indicate that instrumental aggression is observable in the first decade of life (Price \& Dodge, 1989). In adult offender samples, instrumental aggression is frequently perpetrated by highly dissocial and predatory offenders (Cornell, Warren, Hawk, Stafford, Oram, \& Pine, 1996). Cornell et al. (1996) found a positive relationship between the commission of instrumental crimes and offender scores on the Psychopathy Checklist-Revised (Hare, 1991). Determining the differences between aggression that is secondary to perceived provocation (reactive aggression) and that which is premeditated, volitional, and pursuant of specific goals (instrumental aggression) can be useful in understanding patterns of intergroup violence within a community, as well as providing insight into the motivations and behavior of the violent bias offender.
Instrumental and reactive forms of aggression illustrate two prototypical forms of bias-motivated aggression. In reactive aggression, hate crimes are committed defensively and without preplanning in the name of in-group protection, what Green, Strolovitch, and Wong (1997) have referred to as the "defended neighborhoods" hypothesis. In reactive bias crimes, provocation of the offender is frequently secondary to benign contact with members of a denigrated out-group. The preexisting assumption of threat to the offender's in-group is an important motivator in such pseudorevenge bias offenses. Reactive bias crimes are also seen in interethnic gang conflict, in which protection of illicit markets may result in aggression against out-group persons. The protective reactive bias criminal may assume a role as a member of a hate-motivated vigilante mob or as a councilperson of a community watch group or may engage in "lone wolf" vandalism against minority members of a community. In contrast, bias-motivated instrumental aggression is marked by the premeditated and predatory pursuit of out-group persons. The goal orientation of instrumental bias aggression may reflect the offender's demonstration of social dominance and underscore a greater ideological resolve that guides the offender in selection of a victim. The intensity or prominence of bias motivation of the offender may influence the form of aggression (e.g., the goal directedness) found in the commission of a hate crime.

\section{Assessing Violence Risk of Bias-Motivated Offenders}

Although many hate crimes are indeed violent, it is unclear whether the bias-motivated offender poses a significant risk for violence. Given the unique motivation for commission of a hate crime, it is uncertain whether offenders are comparable to other criminal groups in regards to risk for violent recidivism. The recent advent of actuarial risk assessment methodologies makes clear the role of childhood and development problems in estimating risk of violence (Menzies, Webster, McMain, Staley, \& Scaglione, 1994). Actuarial models provide a criterion-rich and systematic approach to evaluating the relative level of risk for violence. An important issue in violence risk assessment concerns the presence of psychopathy in an offender group, such as spousal batterers (Coan, Gottman, Babcock, \& Jacobson, 1997), sexual offenders (Boer, Wilson, Gauthier, \& Hart, 1997), or hate crime perpetrators. As has been documented by Hare (1991), psychopathy consists of two primary dimensions, aggressive narcissism and a chronically 
antisocial lifestyle. This widely researched construct has been found to be a valid predictor of future violence and postincarceration recidivism (Salekin, Roger, \& Sewell, 1996). Conceptually, psychopathy may share some characteristics associated with out-group hostility, which are independent of an ideological or bias motivation. Bell's (1980) clinical formulation of this disorder proposed that in-group entitlement, narcissism, and grandiosity constitute core diagnostic characteristics of the aggressive racist. Additionally, Ezekiel (1995) has provided vivid evidence of the economically marginalized, parasitic, and rootless lifestyles of many members of hate gangs. Taken together, the work of Bell and Ezekiel suggest that although psychopaths are typically bereft of an ideological worldview per se, they do share many of the same clinical characteristics found in the pathological racist as described by Bell and likewise engage in a dissocial and tumultuous lifestyle as evidenced by many hate group members.

As law enforcement has become more committed to prosecuting hate crimes, the identification of the offender's bias motivation becomes more important. The analysis of the development history, patterns of aggression, and risk for future violence can provide guidance about the rehabilitation needs of bias offenders. In the current study, the following questions were examined: (a) Can the bias motivation of hate crime offenders be understood as a multidimensional construct, and, if so, what are the base rates for the signifiers of their motivation? (b) Are differences between reactive and instrumental aggression related to the degree or prominence of the offender's bias motivation? and (c) Do actuarial assessment systems reveal substantial risk for violent recidivism for such offenders, as characterized on the HCR-20 and Psychopathy Checklist: Screening Version (PCL:SV) rating systems?

\section{Method}

\section{Sample}

The sample consisted of 58 convicted hate crime offenders in Los Angeles County, California. The offenders were identified via review of court records for the calendar years from 1995 to 1997 . The sample constituted all of the convicted bias offenders in Los Angeles County during this period, yet made up only $3.24 \%$ of the total reported hate crimes in which there was an identified perpetrator. This small percentage of attained convictions out of the total reported bias crimes is consistent with California state data. In 1997 , for example, there were 1,831 hate crimes reported to law enforcement in the state of California, with an additional
313 complaints for offenses identified as being bias motivated that were filed with city and county district attorney offices. Of these 2,144 offenses, 223 led to convictions as hate crimes. In other words, only $12 \%$ of the statewide reported hate crimes resulted in criminal convictions (California State Department of Justice, 1998).

\section{Measures}

Bias Motivation Profile (BMP). On the basis of record review, four signifier variables of bias motivation were recorded. Ratings were assigned for (a) a history of biasmotivated aggression, (b) membership in a hate group or gang at time of commission of the index crime, (c) articulated hate speech during the commission of the crime, and (d) the presence of hate iconography (literature, art, music, body tattoos, or neo-Nazi garb) at the time of the crime. Each of these signifier variables was rated on a 3-point scale (i.e., 2 = signifier is clearly present, 1 = signifier is possibly present, and $0=$ signifier is absent), with a potential range of $0-8$. For the current sample, the mean score of the aggregated BMP signifier variables was $4.00(S D=1.75)$. The clear presence of one of more of these signifiers was used to classify offenders who evidenced a prominent bias component vis-à-vis other members of the sample group.

PCL:SV (Hart, Cox, \& Hare, 1995). The PCL:SV is a modified version of the Psychopathy Checklist-Revised (PCL-R, Hare, 1991). The PCL:SV has been used in numerous research programs, including the Macarthur Violence Study (Steadman et al., 2000). The PCL:SV consists of 16 items, which measure the core characteristics of psychopathy. Like the PCL-R, the PCL:SV yields a two-factor model of psychopathy. Section 1 represents characteristics of narcissistic personality disorder. It describes an individual's tendencies to be selfish, remorseless, and exploitative of others. Section 2 measures an asocial, unstable, and antisocial lifestyle. As reported in the technical manual, the PCL:SV has a total mean score of 16.41 with a forensic-nonpsychiatric sample $(S D=3.49, S E M=1.80)$. The recommended cut score for diagnostic purposes is 18 to classify a subject as a prototypical psychopath. With the current sample, the total scale score was $16.48(S D=3.27)$. The mean score of Section 1 was $7.43(S D=1.83)$, and for Section 2, the mean score was $9.32(S D=2.17)$. The internal (alpha) reliability for the PCL:SV was .84; the interrater coefficient was .80. The correlation of Section 1 and Section 2 of the PCL:SV was .39. As has been established in prior research on offenders, the study of psychopathy can be accomplished via record review (Harpur, Hare, \& Hakstian, 1989). There have been numerous published studies that have used ratings based on record review methods for the classification of psychopathic offenders (Harris, Rice, \& Cormier, 1991; Wong, 1988).

HCR-20 (Webster, Douglas, Eaves, \& Hart, 1997). The HCR-20 is a 20-item rating scale concerned with identifying the risk factors of violent behavior. The 20 items are classified into a 10-item Historical $(\mathrm{H})$ scale, a 5-item Clinical (C) scale, and a 5-item Risk Management (R) scale. These 20 dimensions have been found in prior research to predict 
future violence. The $\mathrm{H}$ criteria include ratings for prior violent and risk activities, the $\mathrm{C}$ criteria define the attitudes and clinical status of the offender at time of the evaluation, and the $\mathrm{R}$ criteria reflect the presence of destabilizing factors related to violent recidivism. Each item is scored by the examiner on a 3-point scale to denote whether the specific variable (e.g., "history of previous violence") is clearly present, somewhat present, or absent (scored 2, 1, and 0 , respectively). The HCR-20 integrates static and unchangeable historical criteria with dynamic criteria of current risk status. The HCR-20 has been used in studies with mixed offender groups (Douglas, Klassen, Ross, Hart, \& Webster, $1998)$, yielding an $\mathrm{H}$ score of $12.45(S D=3.60)$, a $\mathrm{C}$ score of $5.47(S D=2.46)$, and an R score of $6.64(S D=2.30)$. The HCR-20 scales were found to correlate with ratings for psychopathy and psychopathology. With the current sample, the mean $\mathrm{H}$ scale score was 9.35 ( $S D=5.72$; interrater reliability $=.94 ; \alpha=.94)$, the mean $\mathrm{C}$ scale score was 6.11 $(S D=1.85$; interrater reliability $=.88 ; \alpha=.92)$, and the mean $\mathrm{R}$ scale score was $6.77(S D=2.96$; interrater reliability $=.91 ; \alpha=.86$ ).

Cornell Aggression Index (Cornell et al., 1996). This rating scale examines the salient features of a specific criminal event, specifically in terms of distinguishing between instrumental and reactive aggression. The rating system assesses the form of aggression evidenced by the perpetrator. The Cornell Aggression Index consists of nine rating dimensions. The first dimension identifies whether the crime constitutes instrumental or reactive aggression. The four rating values for this criteria range from clearly instrumental, primary instrumental/secondary reactive, primary reactive/ secondary instrumental, to clearly reactive. The remaining eight secondary rating dimensions then consider specific characteristics of aggression, some of which are used to distinguish between instrumental and reactive criminal behavior. For example, planning and goal directedness are typically related to instrumental crimes, whereas the offender's perceived provocation and level of arousal are features of reactive aggression. This rating system has been used to evaluate mixed offender groups with both adults and adolescents. In the current study, the mean interrater coefficient of reliability for all nine dimensions was .84 , with a range from .98 (presence of psychosis) to .76 (level of offender arousal).

Cormier-Lang Crime Index (Quincey, Harris, Rice, \& Cormier, 1998). This rating scale is derived from an earlier system developed by Akman and Normandeau (1967) to quantify the criminal history of the offender. As Quincey et al. (1998) noted, "This system can be used when only official police 'rap sheet' information is available" (p. 250). The rating system is organized into Class 1 offenses, representing values assigned to violent and aggressive crimes, Class 2 offenses for nonaggressive crimes (e.g., theft, fraud), and a total score for all offenses reported. In the current study, the Cormier-Lang Crime Index values were computed for the hate index crime, the total prior criminal history of the hate crime perpetrators, and for the Los Angeles County baseline sample for the hate (index) crime. Aggregate values for Class 1 (violent), Class 2 (nonviolent), and total scores were computed for each of these groups. With the convicted offender sample, the aggregated total score for the criminal history was $15.40(S D=18.92)$. For the hate (index) crime, the total Cormier-Lang Crime Index score was $11.43(S D=$ 6.49); the Los Angeles County baseline index crime score on the Cormier-Lang Crime Index was $8.00(S D=3.65)$.

\section{Procedure}

All of the offenses that led to conviction were identified as bias motivated through a multistep classification process. For an offense to be classified as a hate crime, the victim had to report the incident to law enforcement, have the responding officer note the incident was bias related on the crime report, have the precinct hate crimes coordinator review and affirm that the offense was bias motivated, and then, in turn, report the crime to the Los Angeles District Attorney's Office. The crime report was then reviewed by a staff attorney of the District Attorney's Office Hate Crime Unit, who determined whether the offense provided sufficient grounds to be prosecuted under the state hate crime statutes. This multistep process allows for the removal of events that do not meet the legal standard of being both a crime and bias motivated. Information on the index crime was recorded, as reported by the responding officer, for bias crime motive (e.g., race-ethnicity, religion), number of offenders involved in the crime, and demographic characteristics (gender, race, and age) of the perpetrator(s).

Offender personal history was determined via record review of the crime report, review of the offender's rap sheet of prior arrests and convictions, and evidence presented in the trial proceedings. The criminal history was coded in accordance with HCR-20 and PCL:SV rating criteria; this included determining the number of prior convictions and the number of prior violent convictions. Review of crime reports and testimony from the trial transcripts were coded by four members of a research team, all of whom were students enrolled in psychology training programs at the time. From these two sources, ratings were assigned for the Cormier- Lang Crime Index and Cornell Aggression Index. I provided training and consultation in the coding and rating of these measures.

Analysis of the offender's developmental history, inclusive of childhood and adolescent problems, was recorded from review of the probationary record. Ratings were assigned in accordance with HCR-20 criteria for family problems (divorce and violence in the home), educational problems, history of psychiatric treatment, drug-alcohol dependence, and employment problems noted in the work history. Content analysis of the records was used for scoring the PCL:SV, BMP, and actuarial scales; I coded these.

\section{Results}

The demographic characteristics of the offender sample indicate that these offenses were overwhelmingly perpetrated by young men. Of the 58 convicted 
hate offenders, $91.4 \%(n=53)$ were men and $8.6 \%$ $(n=5)$ were women. The mean age of the offenders was 24.5 years $(S D=8.07$, range $=16-44)$. Eightyeight percent of the offenders were adults at the time of the hate crime. The race-ethnicity of the offenders included 15.5\% African American, 3.4\% Asian Pacific, 32.8\% European White, and 48.3\% Latino. The distribution of the offender's race and ethnicity is approximate to that of the demography of Los Angeles County.

The first research question sought to determine the base rates of the individual signifiers of bias motivation in the commission of a hate crime. Analysis of the BMP dimensions indicated that $13.8 \%$ $(n=8)$ of the offenders belonged to an organized hate gang or group, that $22.4 \%(n=13)$ possessed hate paraphernalia-iconography (books, graphic images, or hate tattoos on their body) at the time of the crime, and that $10.3 \%(n=6)$ of the individuals had a history of prior hate-motivated violence. The mean intercorrelation for the four BMP variables was .21, ranging from .08 to .43 . When considered collectively, there was compelling evidence that $25.9 \%(n=15)$ of the offenders clearly evidenced (i.e., score of 2 on the BMP criteria) one or more of the signifiers of a bias motivation.

The hate crimes included physical assault (48.3\%), attempted murder (5.2\%), and homicide (3.4\%); a minority of the offenses (17.3\%) were property crimes (i.e., vandalism or hate graffiti). Only $25.8 \%$ of the crimes included charges of robbery or extortion, that is, the majority of the crimes were unrelated to the pursuit of material or financial reward. Roughly one quarter of the index crimes included charges of restriction of federally protected civil rights (22.4\%). Victim selection was predominantly related to race and ethnicity-accounting for $80 \%$ of the current cases $(n=46)$. Another $11(19 \%)$ of the hate crimes were motivated by the victim's sexual orientation; there was one case motivated by gender bias, and no cases of religious bias crimes.

Patterns of aggression based on Cornell Aggression Index ratings of the offense revealed the majority (79\%) of the offenders engaged in instrumental forms of aggression. The majority of the bias crimes were committed by multiple perpetrators $(M=2.29$, $S D=1.58$ ). Only $27.6 \%$ of the offenders in the current sample acted alone. The number of offenders involved in the index crime was correlated with the Cornell Aggression Index ratings for the degree of instrumentality $(r=.36, p<.01)$, planning $(r=.21$, $p<.05$ ), (heightened) level of offender arousal $(r=.27, p<.05)$, (heightened) severity of violence $(r=.26, p<.01)$, lower levels of prior relationship familiarity $(r=.27, p<.04)$ with the victim, and (lower) levels of individual offender psychopathol$\operatorname{ogy}(r=-.36, p<.01)$.

The second research question sought to determine whether the type of aggression varied by level of bias motivation. Chi-square analyses were computed for the offenders who clearly evidenced one or more of the bias motivation dimensions $(n=15)$ in comparison with different offenders who did not clearly evidence one or more of the BMP criteria $(n=43)$ groups with the Cornell Aggression Index ratings. Results revealed that the highly bias-motivated offenders engaged in more instrumental (i.e., predatory and premeditated) crimes than reactive crimes, $\chi^{2}(3, N=58)=5.32, p<.02$; evidenced greater goal orientation, $\chi^{2}(3, N=58)=8.62, p<.05$; and were less likely to have had a prior relationship with their victims, $\chi^{2}(4, N=58)=5.94, p<.03$. In addition, highly bias-motivated offenders exclusively perpetrated race-ethnic-motivated crimes, $\chi^{2}(2, N=$ $58)=5.48, p<.02$, rather than sexual-orientation or gender-motivated crimes. Table 1 summarizes these findings.

Estimation of risk for violence for the hate offenders (the third research question) was assessed on the HCR-20 and PCL:SV rating scales. Findings indicated that the risk indicators were, as would be anticipated, intercorrelated with one another. The PCL:SV was significantly correlated with the HCR-20 H $(r=.51$, $p<.01), \mathrm{C}(r=.42, p<.01), \mathrm{R}(r=.49, p<.01)$, and total scale scores $(r=.52, p<.01)$. Review of the probationary records revealed a variety of developmental problems related to risk for violence and antisocial behavior in general. Fifty-eight percent of the sample had a history of substance abuse; nearly 1 in 4 had a history of psychiatric treatment prior to commission of the bias crime (22.4\%); and a similar number $(24.1 \%)$ evidenced educational problems, including failure to complete high school, enrollment in special education programs, and/or school suspension. Approximately one third (37.9\%) of the sample had family histories marked by parental separation and/or domestic violence. At the time of commission of the hate crime, $6.9 \%$ of the offenders were employed in regular (i.e., full time) work, $42.4 \%$ were in marginal or part-time occupations, and $45.5 \%$ were unemployed (though some of these were likely employed in illicit work as career criminals). At the time of the hate crime, $87 \%$ of the offenders had prior criminal convictions, and $60 \%$ had one or more prior violent convictions. The mean number of prior convictions was 5.38 $(S D=0.98)$. For the current sample, developmental 
Table 1

Cornell Aggression Index Violence Ratings With Offender Number and Bias Component

\begin{tabular}{|c|c|c|c|c|}
\hline Ratings for hate crime & $n$ & $\%$ & $\begin{array}{l}\text { Total no. } \\
\text { offenders }^{\text {a }}\end{array}$ & $\begin{array}{c}\text { Bias } \\
\text { component } \\
\chi^{2}\end{array}$ \\
\hline Instrumental vs. reactive aggression & & & $.36^{* *}$ & $5.31 *$ \\
\hline Instrumental aggression & 29 & 50.0 & & \\
\hline Primarily instrumental/some reactive qualities & 6 & 10.3 & & \\
\hline Primarily reactive/some instrumental qualities & 11 & 19.0 & & \\
\hline Clearly reactive hostile aggression & 12 & 20.7 & & \\
\hline Planning & & & $.21 *$ & 0.86 \\
\hline Extensive planning/rehearsal & 7 & 12.1 & & \\
\hline Moderate planning (more than $24 \mathrm{hr}$ ) & 2 & 3.4 & & \\
\hline Some planning (action within $24 \mathrm{hr}$ ) & 6 & 10.3 & & \\
\hline Very little or no planning & 43 & 12.1 & & \\
\hline Goal directedness & & & $.37 * *$ & $8.62 * *$ \\
\hline Clear unequivocal goal directedness & 31 & 53.4 & & \\
\hline Primary goal directedness, w/other motives & 11 & 19.0 & & \\
\hline Secondary goal directedness & 9 & 15.5 & & \\
\hline No apparent goal directedness & 7 & 12.1 & & \\
\hline Provocation & & & -.03 & 1.91 \\
\hline Exceptionally strong/repeated assault/abuse & 0 & & & \\
\hline Very strong provocation (assault) & 1 & 1.7 & & \\
\hline Strong & 0 & & & \\
\hline Moderate provocation/serious argument/threat & 2 & 3.4 & & \\
\hline Mild provocation/minor argument & 12 & 20.7 & & \\
\hline No apparent provocation & 43 & 74.1 & & \\
\hline Offender arousal & & & $.21 *$ & 4.18 \\
\hline Enraged, furious/“out of control” & 15 & 25.9 & & \\
\hline Angry, mad, extremely frightened & 7 & 12.1 & & \\
\hline Excited, very nervous/anxious & 25 & 43.1 & & \\
\hline Calm or tense at most & 11 & 25.9 & & \\
\hline Severity of violence & & & $.26^{*}$ & 4.07 \\
\hline Extreme homicide (multiple victims/mutilation) & 0 & & & \\
\hline Homicide & 2 & 3.4 & & \\
\hline Severe injury/lasting impairment & 3 & 5.2 & & \\
\hline Serious injury requiring substantial hospitalization & 6 & 10.3 & & \\
\hline Minor injury requiring minor medical treatment & 18 & 31.0 & & \\
\hline Assault without injury & 9 & 15.5 & & \\
\hline No assault/threat & 20 & 34.5 & & \\
\hline Relationship with victim & & & $-.27 *$ & $5.93 *$ \\
\hline Very close relationship/family member & 1 & 1.7 & & \\
\hline Close relationship & 1 & 1.7 & & \\
\hline Specific relationship & 11 & 19.0 & & \\
\hline Acquaintance & 2 & 1.7 & & \\
\hline Stranger & 44 & 75.9 & & \\
\hline Intoxication & & & .16 & 2.02 \\
\hline Severe intoxication/very impaired & 1 & 1.6 & & \\
\hline Intoxicated & 18 & 31.0 & & \\
\hline Mild intoxication & 2 & 3.4 & & \\
\hline Not intoxicated & 37 & 63.8 & & \\
\hline Presence of psychosis & & & $-.36^{* *}$ & 1.40 \\
\hline Substantial psychotic symptoms & 0 & - & & \\
\hline Moderate psychotic symptoms & 1 & 1.7 & & \\
\hline Nonpsychotic disturbance/depersonalized & 4 & 6.9 & & \\
\hline Not psychotic & 53 & 91.4 & & \\
\hline
\end{tabular}

a'Zero-order correlations.

$* p<.05 . \quad * * p<.01$ 
risk indicators on the HCR-20 $\mathrm{H}$ scale were in the low-average range when compared with a sample of 175 criminal insanity acquittees (Douglas et al., 1998). For the current sample, 27 (47\%) of the offenders had PCL:SV scores falling at or above the diagnostic cut score, suggesting that psychopathy may indeed be a risk issue for this population.

The issue of offender violence risk was additionally examined in regard to the severity of the bias crime. The risk assessment measures and the number of prior criminal acts were examined in relation to the severity of the hate crime. The HCR-20 total score was correlated with the total number of prior offenses $(r=.48$, $p<.01)$ and the number of prior violent crimes $(r=.54, p<.01)$. The PCL:SV was also correlated with the offender's number of prior convictions $(r=.27, p<.01)$ and number of prior violent convictions $(r=.29, p<.01)$. The relationship of these risk predictors to the level of severity of the hate crime (determined on the Cormier-Lang Crime Index) was, however, less consistent. Severity of the hate crime was not significantly correlated with the three HCR-20 scores; the PCL:SV Section 1 score (the narcissism factor) was modestly correlated $(r=.25, p<.05)$ with the severity of violence against the person. Severity of the hate crime was correlated with the number of prior violent convictions $(r=.46, p<.01)$ but not with the total number of all (violent and nonviolent) criminal convictions. The severity of violence of the criminal history scores of the offenders, as determined through the aggregation of the Cormier-Lang Crime Index scores, were in all cases correlated with the HCR-20 risk appraisal values. These findings are reported in Table 2.

\section{Discussion}

These findings illustrate that there is significant within-group variability for the degree of bias motivation for hate crime offenders. Additionally, the low intercorrelation of the four BMP variables indicates there is only a modest overlap between the identified signifiers of the offender's bias motivation. This suggests that the level of bias motivation for perpetrating a hate crime varies within a unique offender group, as represented by the current sample, and that the discernible indicators of hate motivation vary substantially in terms of how it is identified. It is noteworthy that when one or more of these signifiers of bias motivation is clearly present (e.g., prior bias criminality; membership in hate groups; vociferated hate speech; or symbolic representation of hate beliefs in physical garb, literature, or other iconographic form), the nature of aggression is significantly more instrumental, that is, premeditated. These bias-prominent offenders additionally select their victims because of racial animus. This raises the issue as to whether the motivation for perpetrating a sexual-orientation- or religious-based hate crime is distinctly different from the motivations of those targeting victims on the basis of their race or ethnicity.

In the current sample, instrumentally aggressive bias offenders typically engaged in the pursuit of social dominance rather than monetary or material gain. As such, goals of extrinsic reward are largely supplanted by a goal of aggressive domination of outgroup victims. These offenders perpetrated crimes against out-group persons in contexts of benign intergroup contact. Of interest, unlike Cornell et al. (1996,

Table 2

Zero-Order Correlations for HCR-20 Risk Appraisal and Psychopathy Checklist: Screening Version (PCL:SV) Psychopathy Ratings With Cormier-Lang Crime Index and Total Prior Criminal Convictions

\begin{tabular}{|c|c|c|c|c|c|c|c|c|}
\hline \multirow[b]{2}{*}{ Measure } & \multicolumn{6}{|c|}{ Cormier-Lang Crime Index } & \multirow{2}{*}{$\begin{array}{l}\text { Total prior } \\
\text { criminal } \\
\text { convictions }\end{array}$} & \multirow{2}{*}{$\begin{array}{c}\text { Total prior } \\
\text { violent } \\
\text { convictions }\end{array}$} \\
\hline & Hate Class 1 & (Index) Class 2 & Crime total & $\begin{array}{c}\text { Aggregate } \\
\text { Class } 1\end{array}$ & $\begin{array}{c}\text { Criminal } \\
\text { Class } 2\end{array}$ & $\begin{array}{l}\text { History } \\
\text { total }\end{array}$ & & \\
\hline \multicolumn{9}{|l|}{ HCR-20 } \\
\hline Historical & .04 & .13 & .17 & $.39 * *$ & $.54 * * *$ & $.68 * * *$ & $.51 * * *$ & $.54 * * *$ \\
\hline Clinical & -.07 & .10 & .05 & $.30 * *$ & $.47 * * *$ & $.56 * * *$ & $.44 * * *$ & $.47 * * *$ \\
\hline Risk & .10 & .14 & .18 & $.19 *$ & $.34 * *$ & $.45^{* * * *}$ & $.33^{* * *}$ & $.35 * *$ \\
\hline Total score & .04 & .13 & .15 & $.33^{*}$ & $.50 * * *$ & $.63 * * *$ & $.48 * * *$ & $.54 * * *$ \\
\hline \multicolumn{9}{|l|}{ PCL:SV } \\
\hline Section 1 & $.21 *$ & -.03 & .18 & .05 & .13 & $.23 *$ & $.24 *$ & $.23 *$ \\
\hline Section 2 & .17 & -.03 & .12 & .02 & .08 & .09 & $.31 * *$ & $.33 * *$ \\
\hline Total score & $.25 *$ & -.04 & $.19 *$ & .01 & .15 & $.29 * *$ & $.27^{*}$ & $.29 * *$ \\
\hline
\end{tabular}

$* p<.05 . \quad * * p<.01 . \quad * * * p<.001$. 
in the study of non-bias-motivated criminals), the current findings did not reveal a relationship between psychopathy and instrumental aggression. It may be that the bias-motivated offender as a rule is more likely to evidence premeditation in the commission of the hate crime, irrespective of his or her level of psychopathy.

A fairly distinct picture of multiple-offender hate crimes emerges from the data. Multiple-offender hate crimes are significantly more planful, more goal directed, and marked by greater levels of arousal. Additionally, offenders of multiple-perpetrator crimes are less likely to have had a prior relationship with their victim and evidence significantly fewer symptoms of psychopathology than individuals who perpetuate bias crimes. This composite is largely consistent with the study of group-based social bias, most notably in the study of deindividuation (Festinger, Pepitone, \& Newcomb, 1952). Janis (1982) has described the process of deindividuation as the abandonment of individual responsibility and instrumentality, which, in these cases, resulted in the perpetration of violence against out-group persons. These findings suggest that multiple-offender hate crimes are characterized by a dehumanization of both the offender via deindividuation and the target through the targeting of (relationally) unknown victims.

A great deal needs to be understood about the developmental, cognitive, and conative dynamics of offenders of bias crimes. The current findings reveal a markedly antisocial and psychopathic component in a significant number of the offenders of bias crimes. When considered in terms of individual difference factors that are related to future violence, such as childhood problems, the data suggest that hate offenders pose a significant recidivism risk, comparable with that found with many other violent offender groups. The presence of prior violence coupled with a discernible hate ideology should be given considerable attention by prosecutors, probation officers, and mental health professionals alike. These two components together may reveal a great deal about risk for recidivistic bias criminality. Furthermore, these findings underscore the impoverished social and economic realities of many offenders of bias crimes. These social psychological barriers to the reduction of violence risk need to be addressed as well.

An unexpected finding concerns the absence of a relationship between the estimated risk for violenceas found in the HCR-20 criteria-and the severity of the hate crime itself. This indicates that the severity of bias-motivated crimes may be unrelated to the offender's risk for violence in general. Rather, the egregiousness of the hate crime may be a product of the strength of the animus of the offender or the social psychological influence of deindividuation. In this sense, hate crimes may indeed be a special case crime, as Herek et al. (1996) have suggested, when considered in context of the larger population of offenders who frequently demonstrate a pattern of criminality and recurring violence.

Given the high incidence of psychopathic indicators in the sample, it may be that bias-motivated offenders are particularly immune to rehabilitation efforts. This may also be true given the presence of numerous developmental factors associated with violence. This is particularly important given that bias crimes are frequently considered to be a product of educational deficits (e.g., a failure to appreciate diversity in society) that is fueled by self-alienation (and hence addressed via therapeutic efforts to develop greater interpersonal capacity) more so than criminal malice. The use of psychoeducational programs that incorporate tolerance education, interpersonal skill development, and anger management has yet to be proven efficacious in reducing recidivism risk of hate crime offenders. These findings challenge our assumptions that bias offenders frequently belong to hate groups or are thrill-seeking adolescents who demonstrate a lapse in their cultural sensitivity. Rather, the current findings point to the need to address issues of substance abuse, poverty, and reliance on violence as important treatment goals for reduction of recidivism risk.

This study has examined the bias motivation of hate crime offenders via a multidimensional approach. This strategy permits for the determination of the offender's bias motivation through identification of behaviors and articulated attitudes that are inherently hate based. Future research needs to examine both nonviolent (i.e., symbolic) and extremely violent forms of hate criminality with this methodology in the study of offenders of bias-motivated crimes.

\section{References}

Akman, D. D., \& Normandeau, A. (1967). The measurement of crime and delinquency in Canada: A replication study. British Journal of Criminology, 7, 129-149.

Bell, C. C. (1980). Racism: A symptom of the narcissistic personality disorder. Journal of the National Medical Association, 72, 661-665.

Berkowitz, L. (1993). Aggression: Its causes, consequences, and control. Philadelphia: Temple University Press.

Boer, D. P., Wilson, R. J., Gauthier, C. M., \& Hart, S. D. (1997). Assessing risk for sexual violence: Guidelines for clinical practice. In C. D. Webster \& M. A. Jackson (Eds.), 
Impulsivity: Theory, assessment, and treatment (pp. 326342). New York: Guilford Press.

California State Department of Justice. (1998). Hate crime in California. Sacramento, CA: Division of Criminal Justice Information Systems, Bureau of Criminal Information Analysis.

Coan, J., Gottman, J. M., Babcock, J., \& Jacobson, N. (1997). Battering and the male rejection of influence from women. Aggressive Behavior, 23, 375-388.

Cornell, D. G., Warren, J., Hawk, G., Stafford, E., Oram, G., \& Pine, D. (1996). Psychopathy of instrumental and reactive violent offenders. Journal of Consulting and Clinical Psychology, 64, 783-790.

Douglas, K. S., Klassen, C., Ross, D., Hart, S. D., \& Webster, C. D. (1998, August). Psychometric properties of HCR-20 violence assessment scheme in insanity acquittees. Paper presented at the 106th Annual Convention of the American Psychological Association, San Francisco.

Dunbar, E. (1999). Defending the indefensible: A critique and analysis of psycholegal defense arguments of hate crime perpetrators. Journal of Contemporary Criminal Justice, 15, 64-78.

Ehrlich, H. J. (1992). The ecology of anti-gay violence. In G. Herek \& K. Berrill (Eds.), Hate crimes: Confronting violence against lesbians and gay men (pp. 105-112). Newbury Park, CA: Sage.

Ezekiel, R. S. (1995). The racist mind: Portraits of American neo-Nazis and Klansmen. New York: Viking.

Festinger, L., Pepitone, A., \& Newcomb, T. (1952). Some consequences of deindividuation in a group. Journal of Abnormal and Social Psychology, 47, 382-389.

Green, D. P., Glaser, J., \& Rich, A. (1998). From lynching to gay bashing: The elusive connection between economic conditions and hate crime. Journal of Personality and Social Psychology, 75, 82-92.

Green, D. P., Strolovitch, D. Z., \& Wong, J. S. (1997). Defended neighborhoods, integration, and hate crime. Unpublished manuscript.

Hare, R. D. (1991). Manual for the Psychopathy ChecklistRevised. Toronto, Ontario, Canada: MultiHealth Systems.

Harpur, T. J., Hare, R. D., \& Hakstian, A. R. (1989). Twofactor conceptualization of psychopathy: Construct validity and assessment implications. Psychological Assessment, 1, 6-17.

Harris, G. T., Rice, M. E., \& Cormier, C. A. (1991). Psychopathy and violent recidivism. Law and Human Behavior, 15, 625-637.

Hart, S. D., Cox, D. N., \& Hare, R. D. (1995). Manual for the Psychopathy Checklist: Screening Version. Toronto, Ontario, Canada: MultiHealth Systems.
Herek, G., Gillis, R., Cogan, J., \& Glunt, E. (1996). Hate crime victimization among lesbian, gay, and bisexual adults. Journal of Interpersonal Violence, 12, 195-215.

Jacobs, J. B., \& Potter, K. (1998). Hate crimes: Criminal law and identity politics. New York: Oxford University Press.

Janis, I. L. (1982). Victims of groupthink. Boston: Houghton Mifflin.

Levin, B. (1999). Hate crimes: Worse by definition. Journal of Contemporary Criminal Justice, 15, 6-21.

Menzies, R. J., Webster, C. D., McMain, S., Staley, S., \& Scaglione, R. (1994). The dimensions of dangerousness revisited: Assessing forensic predictions about violence. Law and Human Behavior, 18, 1-28.

Price, J. M., \& Dodge, K. A. (1989). Reactive and proactive aggression in childhood: Relations to peers and social context dimension. Journal of Abnormal Child Psychology, 17, 455-471.

Pulkinnen, L. (1987). Offensive and defensive aggressiveness in humans: A longitudinal perspective. Aggressive Behavior, 13, 197-212.

Quincey, V. L., Harris, G. T., Rice, M. E., \& Cormier, C. A. (1998). Violent offenders. Washington, DC: American Psychological Association.

Salekin, R. T., Roger, R., \& Sewell, K. W. (1996). A review and metaanalysis of the Psychopathy Checklist and Psychopathy Checklist-Revised: Predictive validity of dangerousness. Clinical Psychology: Science and Practice, 3, 203-215.

Steadman, H. J., Silver, E., Monahan, J., Appelbaum, P., Clark Robbins, P., Mulvey, E. P., et al. (2000). A classification tree approach to the development of actuarial violence risk assessment tools. Law and Human Behavior, 24, 83-100.

Sullaway, M. E. (in press). Psychological perspectives on hate crime laws. Psychology, Public Policy, and Law.

Webster, C. D., Douglas, K. S., Eaves, S., \& Hart, S. D. (1997). Manual for HCR-20: Assessing risk for violence (Version 2). Odessa, FL: Psychological Assessment Resources.

Wong, S. (1988). Is Hare's Psychopathy Checklist reliable without the interview? Psychological Reports, 62, 931-934.

Received August 28, 2001

Revision received August 19, 2002

Accepted October 25, 2002 